\title{
Design and Experimental Evaluation of PSO and PID Controller based Wireless Room Heating System
}

\author{
Rajesh Singh \\ University of Petroleum and Energy \\ studies,
}

\author{
Piyush Kuchhal, Ph.D. \\ University of Petroleum and Energy \\ studies,
}

\author{
Sushabhan Choudhury \\ University of Petroleum and Energy \\ studies,
}

\author{
Anita Gehlot \\ University of Petroleum and Energy studies,
}

\begin{abstract}
The paper presents the control of $1 \mathrm{kw}$ heaters in $10 * 10 * 10$ cubic feet room area through ZigBee remote. ZigBee Remote is capable to set the desired temperature command to the heater node by the user. Heater node is having dimmer, processing unit and ZigBee modem . The four temperature node is placed in appropriate location in the room and capable to communicate the temperature information to the heater node. Heater node sends the optimized room temperature data which is collected from the four sensor nodes, to the remote. Remote contains the optimized room temperature data and having the facility to feed the desired temperature data to heater node. This will be an intelligent network in which heater node intelligently maintains the room temperature as set by the remote, using PID and Particle Swarm Optimizing (PSO) algorithm on collected data and adjust the voltage levels of heating elements. Remote, heater node and sensor node having communication ability with baud rate of 9600 . sensor nodes are capable to communicate upto 30 meters and remote and heater node is 100 meters. The proposed heater system is an intelligent, low cost and energy efficient.
\end{abstract}

\section{General Terms}

Embedded system, Control system, Communication, Optimizing algorithm

\section{Keywords}

Heater node, Intelligent network, PSO, PID, Sensor node, remote control, sensor node, Zigbee

\section{INTRODUCTION}

Papers on control system, dimming control circuits and different optimization algorithms, are studied. It is observed, that to control the devices like heater, fan, LED lighting, PID controller with PSO algorithm is suitable. D. Ibrahim et. al says, the design of temperature control can be described with various control strategies using microcontroller with the help of feedback control [1]. erome Henri et. al describes, the need of iterative computer algorithm to optimize the energy performance. For this purpose $\mathrm{PSO} / \mathrm{HJ}$ identifies more accurately the global minimum for function [2]. Nikita Kukunura et.al narrates, In Wireless Sensor Networks (WSN), to ensure high quality of service and good sensing coverage the sensors are placed at optimum position. For this purpose PSO has good results, which is based on the swarm intelligence [3]. Particle Swarm Optimization (PSO) was introduced by Kennedy and Eberhart in 1995. It was inspired by the social behavior of birds flocking. Its work on the same way as other optimizing algorithms but give more optimized value of the given data. It is better than other optimizing techniques like genetic algorithm, Ant colony algorithm because of its calculation speed and ease of realization [3]. To determine the heating requirement and energy required to bring system upto desired temperature, several conditions must be considered [4]. I.Khan et.al says, by implementing home energy management, energy consumption can be handled more efficiently. Also home appliance coordination with different tariff schemes is a good solution but have various challenges in implementation [5]. Anita says, wireless sensor networks can be analyzed and controlled with the help of artificial neural network with particle swarm optimization for finding the optimized results for the system [6]. ChingChang Wong et. al narrates, an automatic voltage regulator system with better control performance and comparative study between real valued genetic algorithm and PSO with PID [9]. Vineet Shekher et. al says, PID controller can be tuned by using different methods like Ziegler-nichols, cohen-coon etc, but all methods have some limitations so it is difficult to obtain optimized control by PID controller. With the use of intelligent controller based on genetic algorithm or PSO, optimization can be achieved [11]. Mohammad Ahmadi et.al describes PI controller tunning with Ziegler- Nichols, Genetic algorithm and PSO method to control the level and temperature of CSTH. The simulation confirms that the use of PSO has resulted in better results [12]. S.N. Sivanandam et. al says, PSO is used for load balancing with different approaches and results are compared with Genetic algorithm [13]. Shinichi Imai et. al says, Non- linear systems can be controlled with PID controller. This can be understood by simulation examples [14].

\section{HARDWARE DEVELOPMENT \\ 2.1 Proposed System}

Fig.2.1 shows the system comprising of $1 \mathrm{KW}$ heater placed appropriately in a room size of $10 * 10 * 10$ cubic feet room area, one master node and one remote control. The basic flow of the process is to make the system intelligent by applying PID controller with particle swarm optimization algorithm on master unit which collects the data from all slave nodes, so that a fixed room temperature can be maintained as required by the user and user can select that input by a remote control.

It is required to make the system intelligent because after an interval of time, there is increment in the previous temperature, according to the given formula [4] below:

$$
\begin{aligned}
& \mathrm{KW}=\left\{\mathrm{CFM} * \text { Temp rise }\left({ }^{0} \mathrm{~F}\right)\right\} / 3000 \\
& \text { where, } \mathrm{CFM} \text { is cubic feet } / \mathrm{min}
\end{aligned}
$$

$\mathrm{KW}$ - energy consumed in kilo watt

Once it reached the required temperature, it is necessary to lower it down after a time slot to maintain constant temperature. Above equation (1) shows the relationship between KW heat and rise in temperature in Farenheight. 


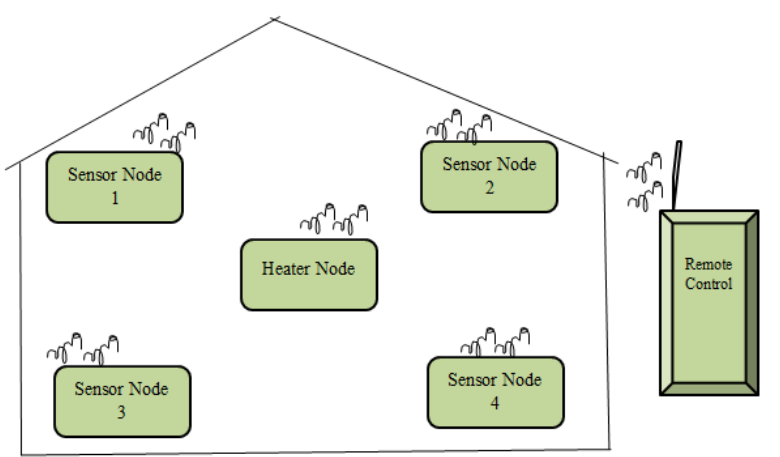

Fig.2.1 Block diagram for the experimental set up of system

Four sensor nodes connected in star topology which is used to collect temperature data form four corner of the room and send it to heater node to use it for controlling PID controller. The temperature collected by temperature sensor node is fed back wirelessly to the heater node. The preset temperature from the user remote acts as the reference input for generating the error signal in closed loop.

\subsection{Remote Control}

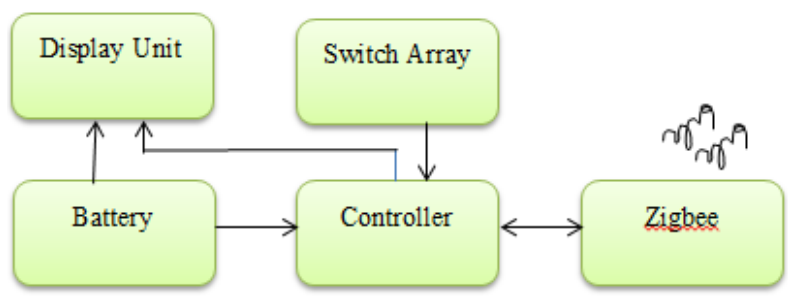

Fig.2.2 Block diagram of remote control

Fig.2.2 shows block diagram of remote which is used for feeding the input by user. It comprises of controller(Atmega16), Display unit(LCD 16x2), Switch array(array of push buttons), battery(9V/200mAh), Zigbee(2.4Ghz). The required temperature is set with the switch array, and it will be displayed on display unit and transmitted to the heater node through Zigbee.

\subsection{Heater Node}

Fig.2.4 shows block diagram of heater node, which comprises of heater(1KW), RTC(1307), EEPROM (24xx), dimmer (MOC3021+Mosfet), temperature sensor L35, controller(Atmega16), Zigbee and power supply (12V/1A adapter). Here, the heater node has major role in the designed system. It will receive the data from remote control and sensor node as well. By getting the information from remote control ,it will fix the required temperature. After some time when temperature reaches the Preset value, PID controller and Particle Swarm Optimization algorithm will be applied on collected data from sensor nodes to provide stable temperature. The heater node will be set at an optimized level in form of $\mathrm{K}_{\mathrm{P}}$ (proportional constant), $\mathrm{K}_{\mathrm{I}}$ (Integral constant), $K_{D}($ Derivative constant ), as shown in Fig.2.5. This process will be continued to maintain the required temperature value. This will be done with the help of temperature sensor and dimmer. Temperature sensor is used to check the exact room temperature and dimmer is used to control the level according to optimized value. RTC is used to provide exact time of temperature data received and EEPROM is used to store the data for further use.
Transfer function for heater element [15] is given by equation (2)

$\mathrm{C}(\mathrm{s})=\left(\mathrm{K}^{*} \mathrm{e}^{-\mathrm{Ts}}\right) /(\mathrm{ts}+1)$

Here

$\mathrm{K}=$ gain of the system

$\mathrm{T}=$ delay time

$\mathrm{t}=$ rise time

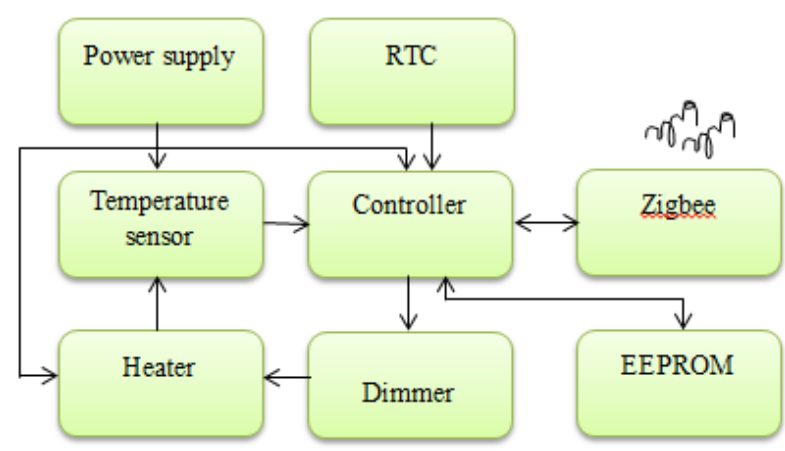

Fig.2.4 Block diagram of heater node

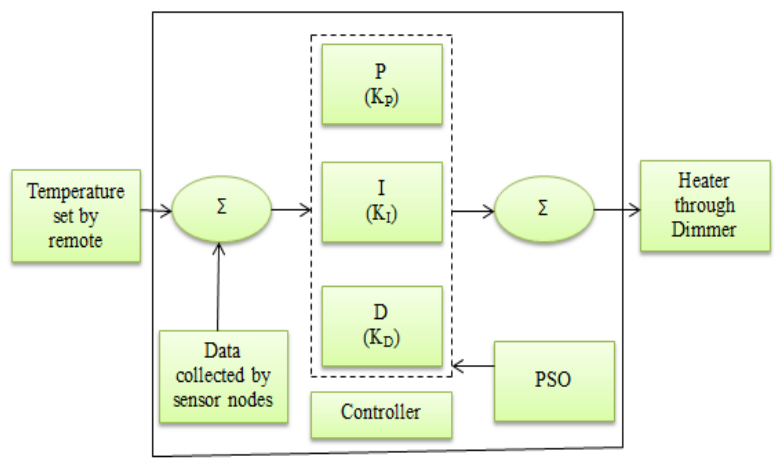

Fig.2.5 Block diagram of controller unit of heater node

\subsection{Sensor Node}

Fig.2.6 shows the block diagram of sensor node. It comprises of temperature sensor(LM35), Zigbee, power supple (battery $9 \mathrm{~V} / 200 \mathrm{mAh})$ and $\operatorname{LCD}(16 \times 2)$. This node is mainly having a temperature sensor which will sense the room temperature and send it to heater node through Zigbee. Processing unit is microcontroller.

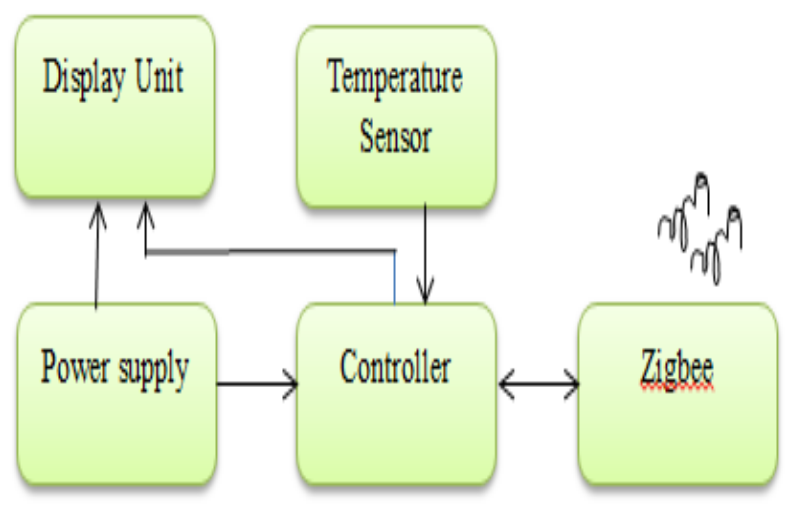

Fig.2.6 Block diagram of sensor node 


\section{SOFTWARE DEVELOPMENT}

\subsection{Algorithm for PID controller with PSO}

1. Input all the desired constraints $\left(M, T_{s}, T_{r}\right)$,heater transfer function, \& PSO constants with no. of particles

2. Initialize the particle positions and velocities

3. Evaluate the fitness value of system with unit step response

4. Calculate system constraints for each particle and total error

5. Compare the individual fitness value of each particle to its previous value, if it is better than previous one, replace with new value i.e. local best position otherwise don't change

6. The position of particle having lowest error is global best value

7. Update position and velocity of particles according to (1)

8. Go back to step (3) and repeat all steps until system constraints are met

Here

M-Overshoot time

$\mathrm{T}_{\mathrm{r}}$-Rising time

$\mathrm{T}_{\mathrm{s}}-$ Settling time

For The optimization of parameters the following equation has been used .

\footnotetext{
$\mathrm{n}=40 ; \quad$ \% Size of the swarm " no of birds "

bird_setp $=40 ; \%$ Maximum number of "birds steps"

dimension $=2 ; \quad \%$ Dimension of the problem

c2 $=1.3 ; \quad \%$ PSO parameter $\mathrm{C} 1$

$\mathrm{c} 1=0.14 ; \quad \%$ PSO parameter $\mathrm{C} 2$

$\mathrm{w}=0.9 ; \quad \%$ pso momentum or inertia

fitness $=0$ *ones(n, bird_setp);

velocity $=\mathrm{w} *$ velocity $+\mathrm{c} 1 *\left(\mathrm{R} 1 . *\left(\mathrm{~L} \_\mathrm{b} \_\right.\right.$position-c_position $\left.)\right)$

$+\mathrm{c} 2 *(\mathrm{R} 2$.*(g_b_position-c_position $))$; and

c_position $=$ c_position + velocity;
}

\subsection{Implementation of PID and PSO}

The simulation for PID and PSO has been done with MATLAB Simulink. First PID controller was realized with the MATLAB and M (Overshoot time), $\mathrm{T}_{\mathrm{r}}$ (Rising time) and $\mathrm{T}_{\mathrm{s}}$ (Settling time), $\mathrm{K}_{\mathrm{P}}, \mathrm{K}_{\mathrm{I}}, \mathrm{K}_{\mathrm{D}}$ were observed. Fig.3.2 shows

\subsection{Flow Chart of complete system}

Fig.3.1 shows the flow chart for the proposed system

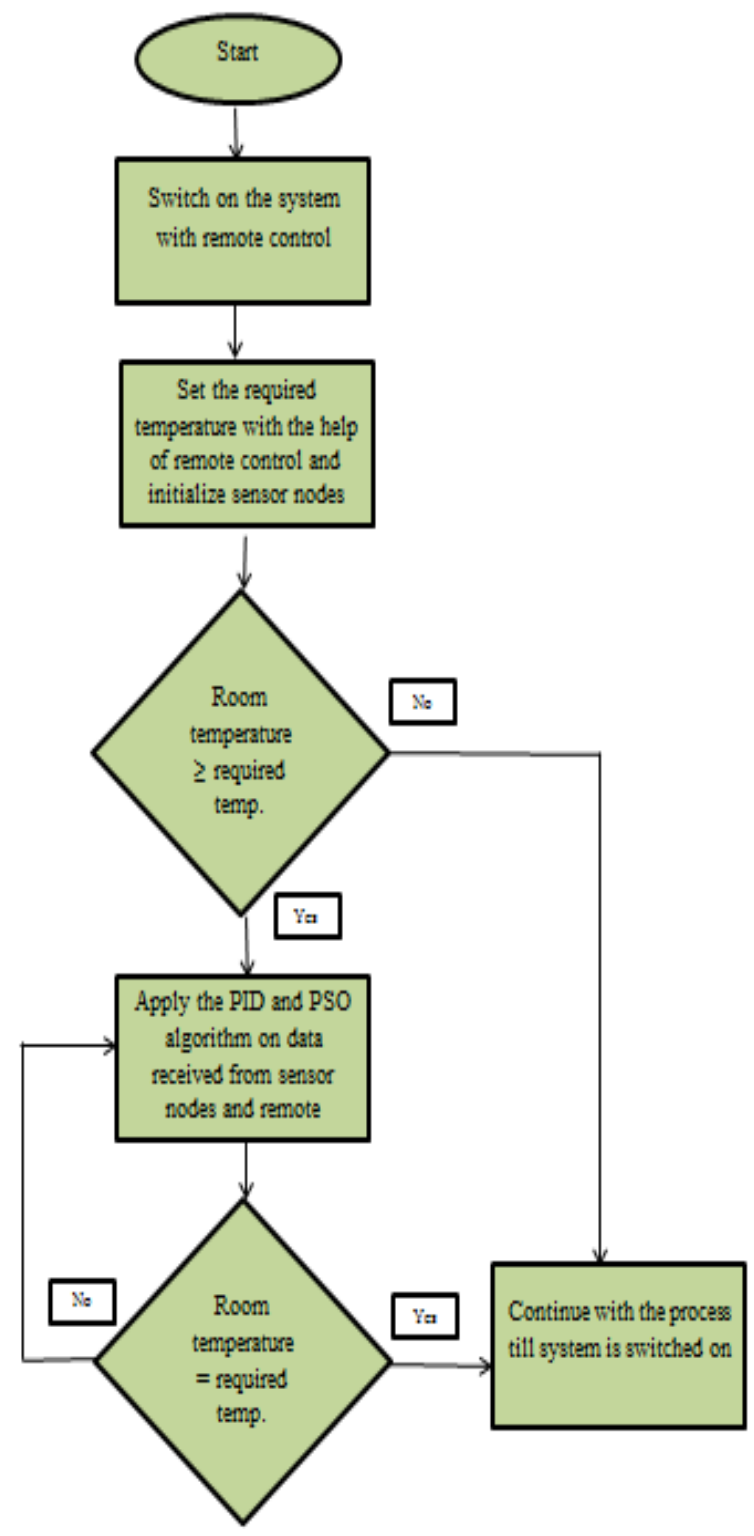

Fig.3.1 Flow diagram of the system

the MATLAB simulation result of PID controller. Then PSO was being implemented to measure optimized values $\mathrm{K}_{\mathrm{P}}, \mathrm{K}_{\mathrm{I}}$, $\mathrm{K}_{\mathrm{D}}$ and set the system by these values and comparative study has been done. Fig.3.3 shows the MATLAB modal for PID+PSO simulation and Fig.3.4 MATLAB simulation results of PID + PSO. 


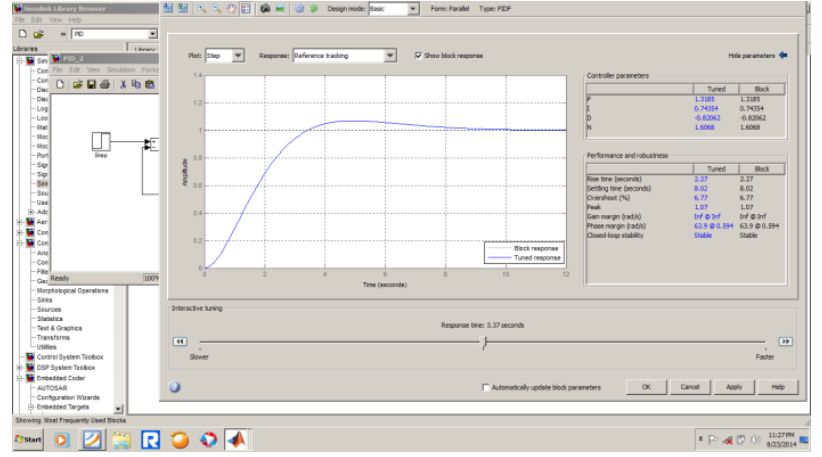

Fig.3.2: MATLAB simulation PID tuned response

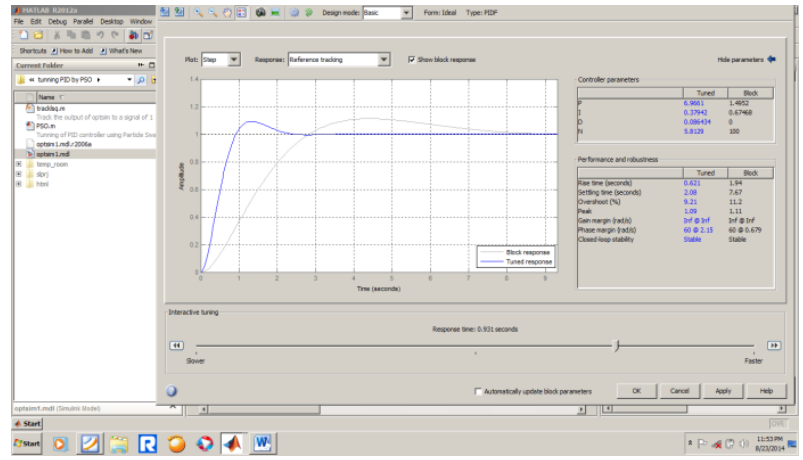

Fig.3.4: Blue color graph PID + PSO tuned response

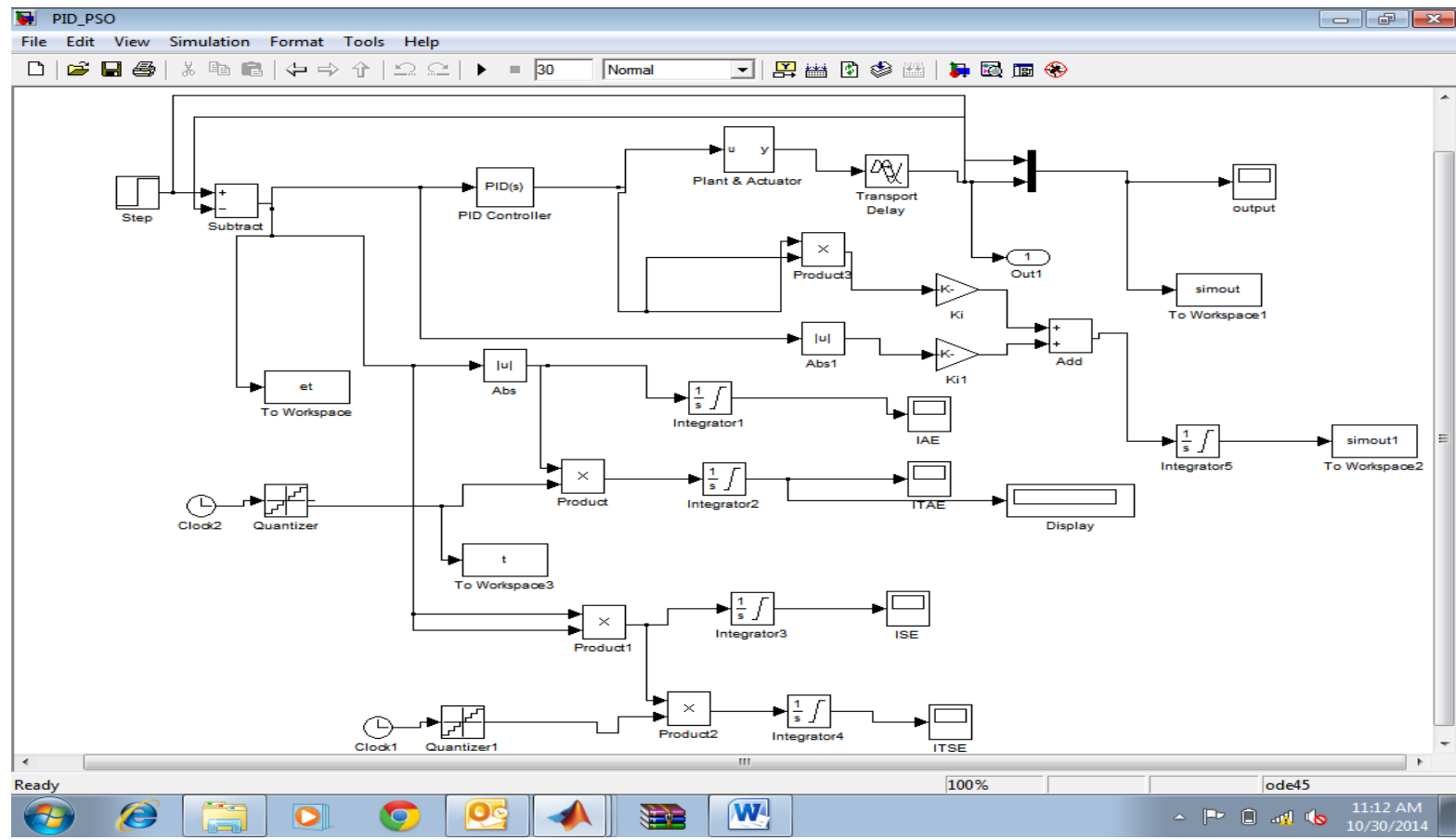

Fig.3.3 MATLAB modal for PID+PSO simulation

Table:1 Comparative Analysis for PID and PID+PSO

\begin{tabular}{|c|c|c|}
\hline & PID & PID + PSO \\
\hline $\mathrm{K}_{\mathrm{P}}$ & 1.318 & 6.966 \\
\hline $\mathrm{K}_{\mathrm{I}}$ & 0.743 & 0.379 \\
\hline $\mathrm{K}_{\mathrm{D}}$ & -0.820 & 0.086 \\
\hline $\mathrm{M}$ & 6.77 & 9.21 \\
\hline $\mathrm{T}_{\mathrm{r}}$ & 2.27 & 0.62 \\
\hline $\mathrm{T}_{\mathrm{s}}$ & 8.02 & 2.08 \\
\hline
\end{tabular}

After studying both methods as shown in table11, it can be concluded that overshoot is high in case of PID + PSO but rising time and settling time has reduced up to a remarkable level. The performance of system is enhanced.

\section{CIRCUIT AND SIMULATION}

Fig.4.1 shows circuit diagram for the system including remote control and heater node. Fig.4.2 shows circuit diagram for sensor node. Fig.4.3 shows Proteus simulation model for the system including remote control and heater node and Fig.4.4 shows Proteus simulation model for sensor node.

Simulation has been done before its hardware implementation to check its proper working. 


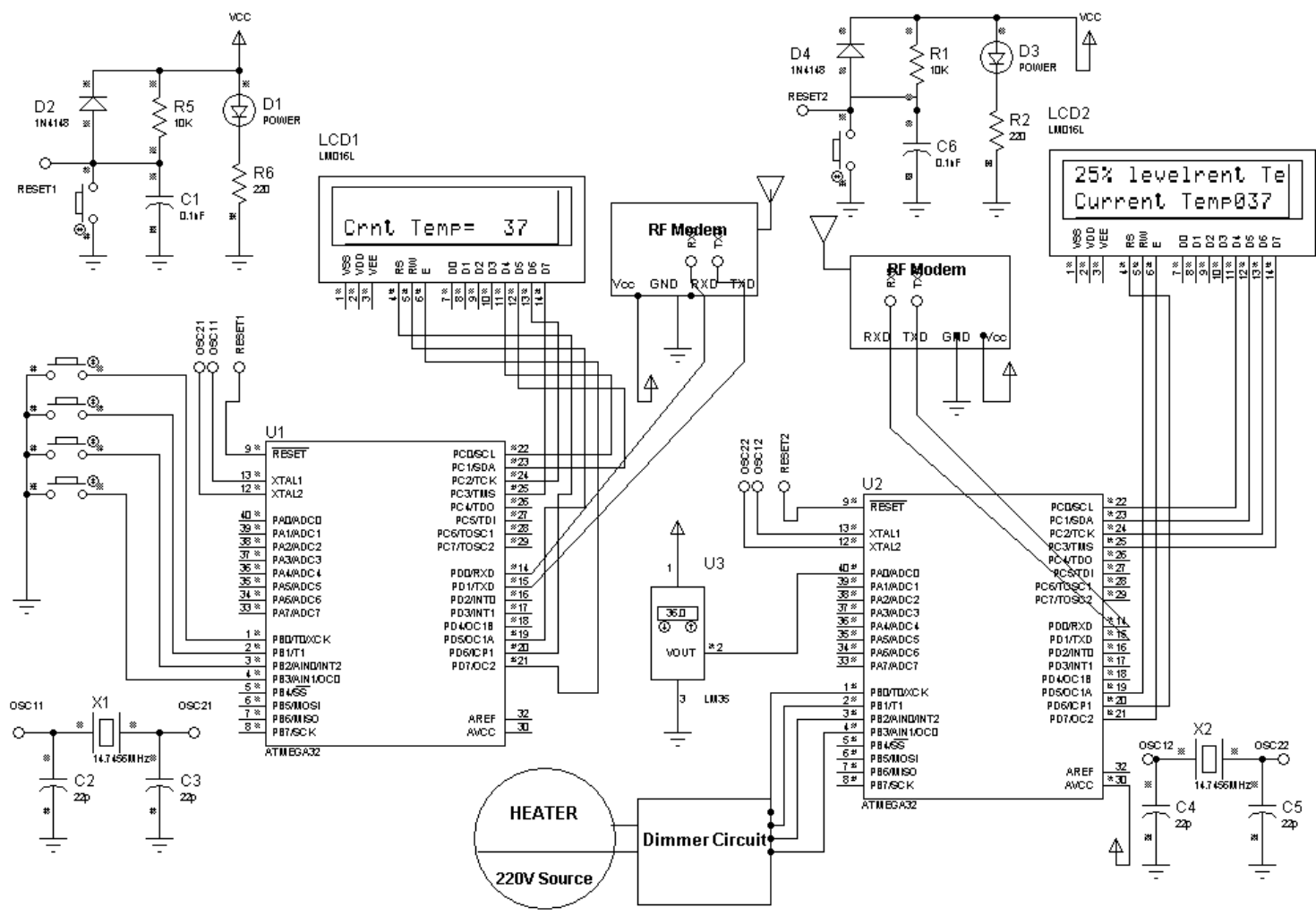

Fig.4.1 Circuit diagram for Remote control and heater node

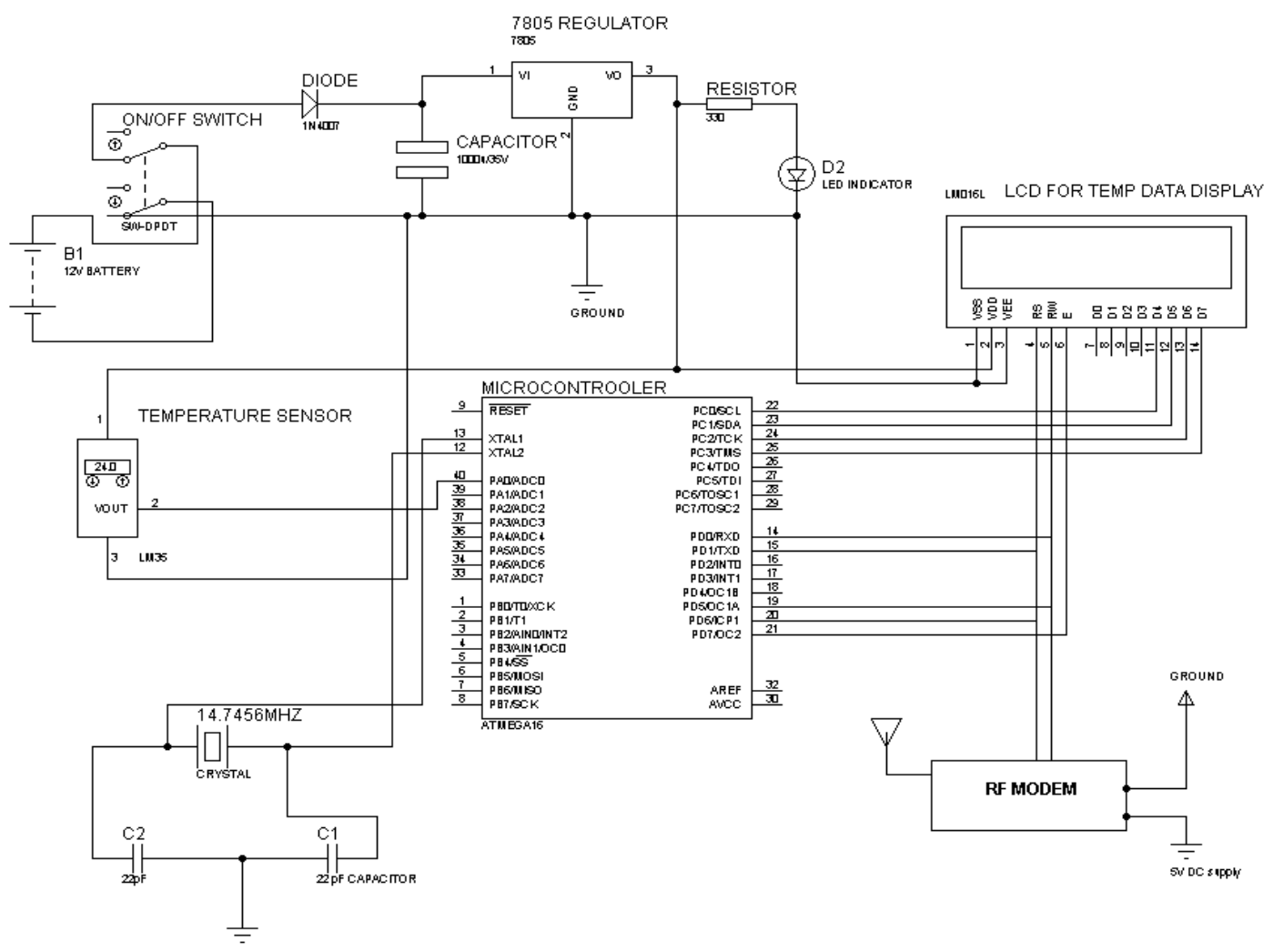

Fig.4.2 Circuit diagram for sensor node 


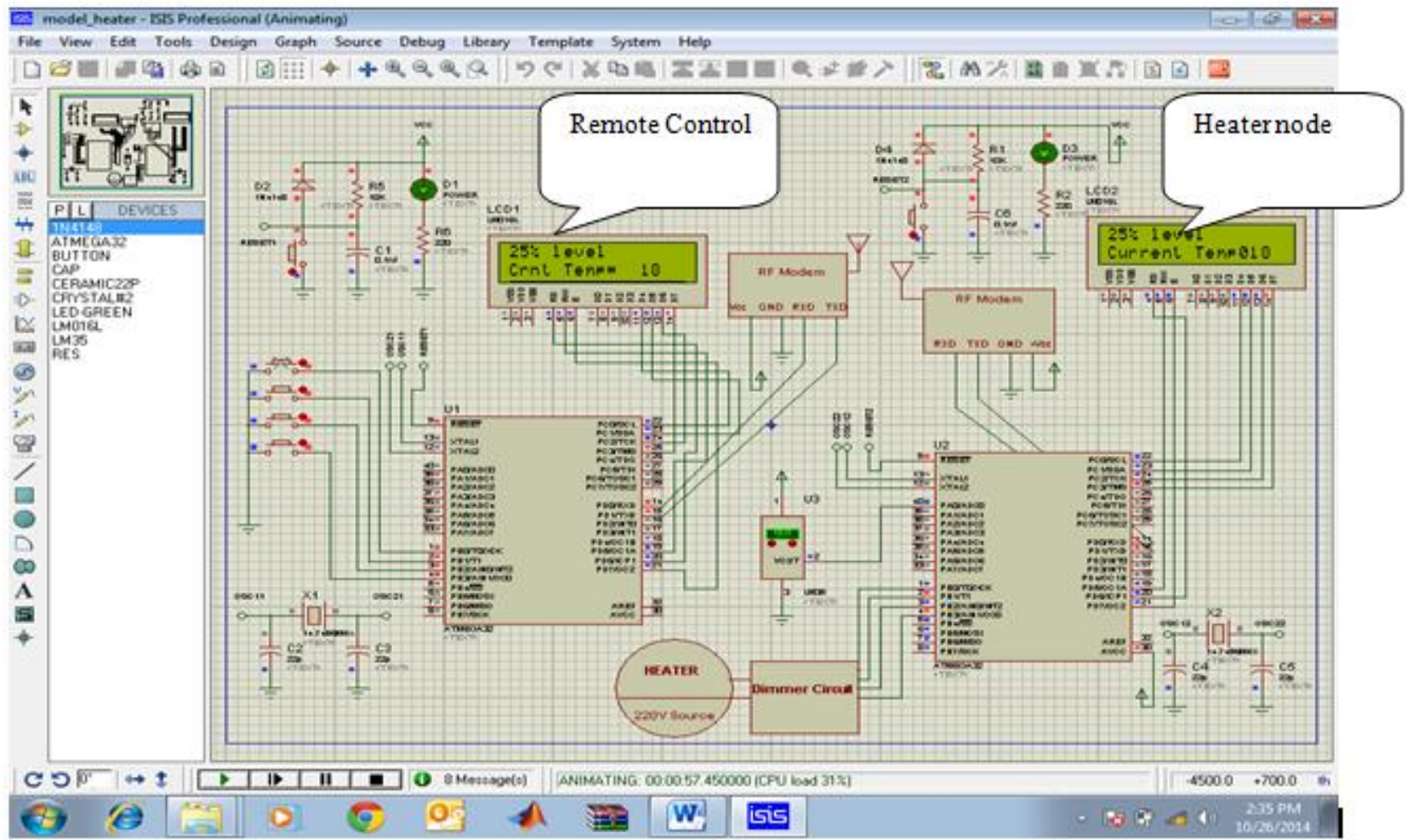

Fig.4.3 Proteus simulation model for the remote control and heater node

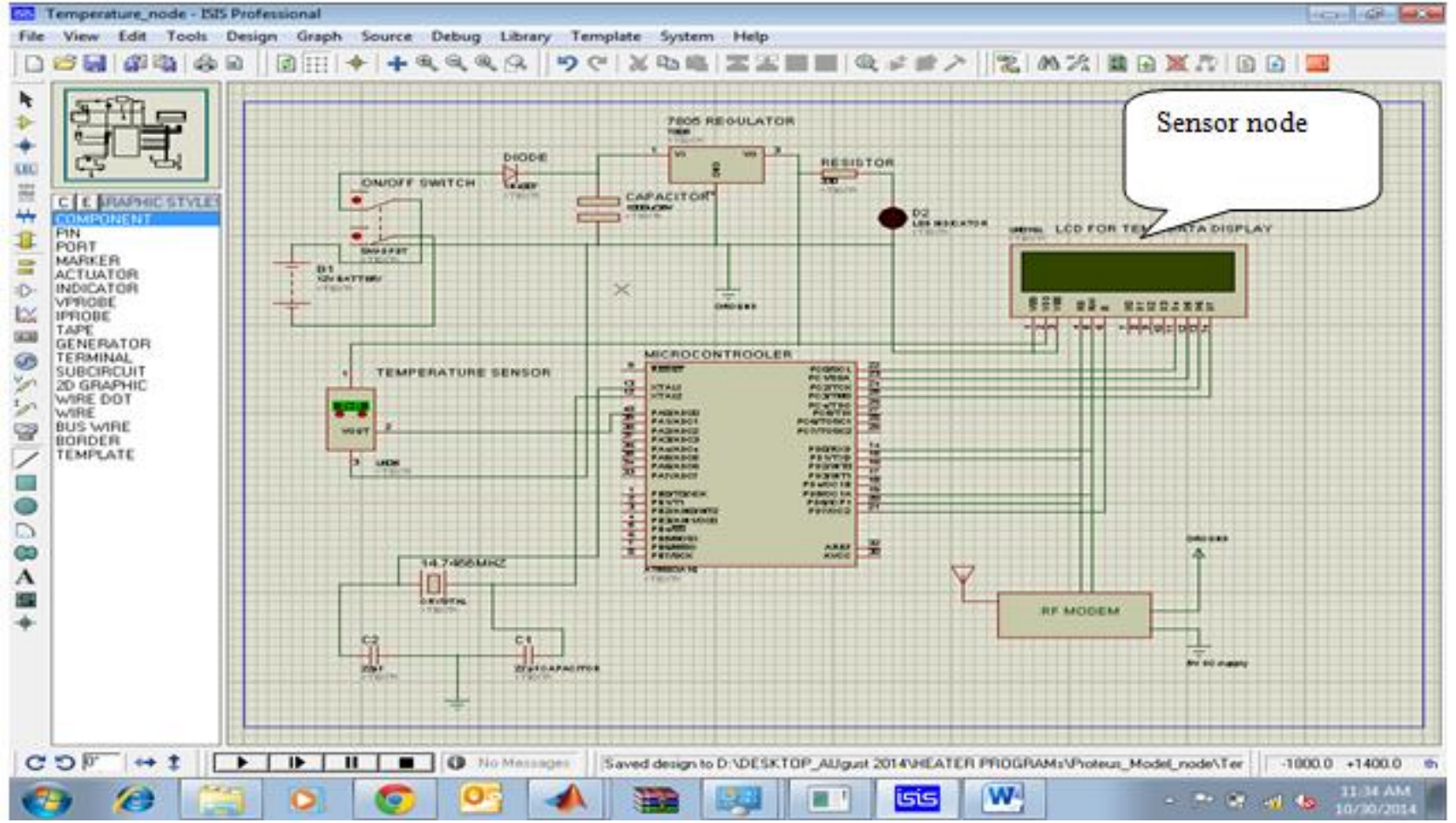

Fig.4.4 Proteus simulation model for sensor node

\section{EXPERIMENTAL SET UP}

Hardware has been implemented and controller was programmed with the optimized values $\mathrm{Kp}, \mathrm{Ki}$ and $\mathrm{Kd}$ using PSO algorithm and the constant preset temperature was observed in the test room of size $10 * 10 * 10$ cubic feet. Fig.5.1 shows developed four sensor nodes connected in star topology which are used to collect temperature data form four corner of the room and send it to heater node to use it for heat control process.

Fig.5.2 shows developed remote control by which room temperature can be set to a required value. Fig.5.3 shows developed heater node which was controlled with the help of proposed algorithm. 


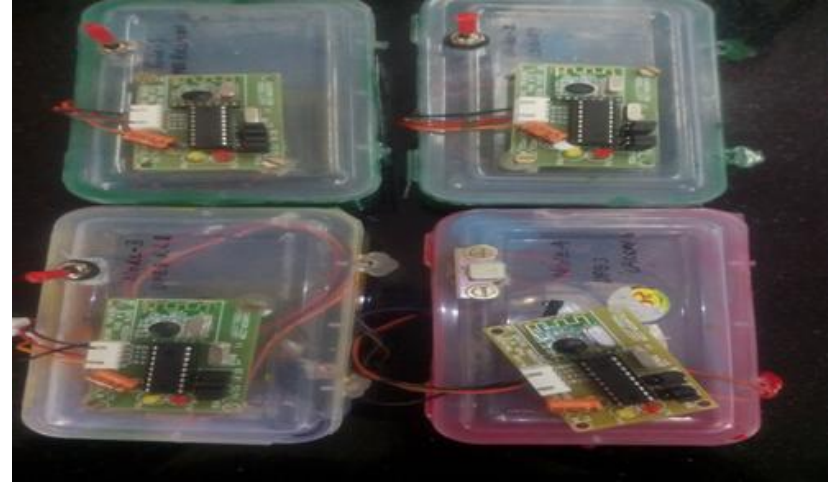

Fig.5.1 Developed Sensor nodes

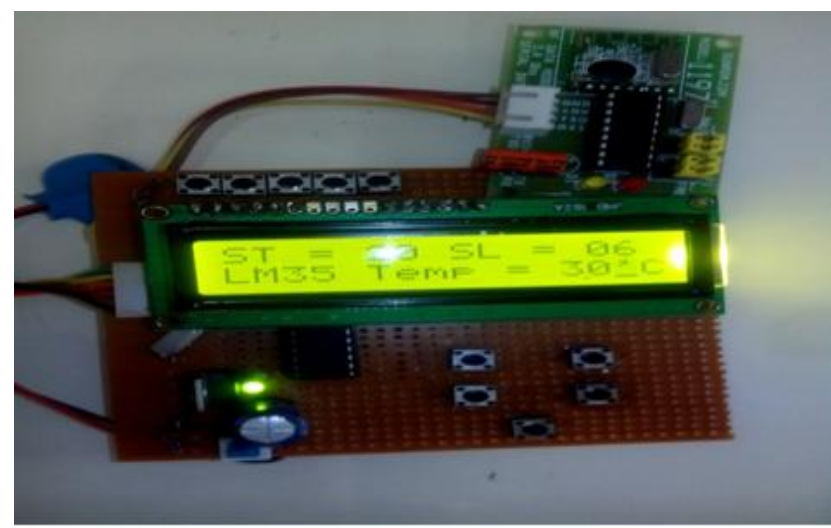

Fig.5.2 Developed Remote Control

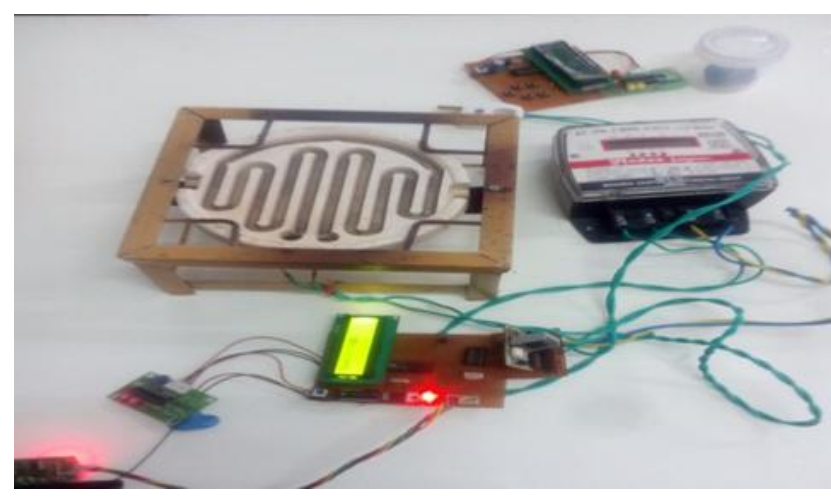

Fig.5.3 Development Heater node

\section{RESULTS AND CONCLUSION}

The table 2 shows the \% saving in power and maintenance of constant temperature of the test room after using the PSO algorithm

Table2: Shows power consumption to maintain temperature at $30^{\circ} \mathrm{C}$

\begin{tabular}{|c|c|c|c|}
\hline $\begin{array}{c}\text { S. } \\
\text { No }\end{array}$ & $\begin{array}{c}\text { Time } \\
\text { duration }\end{array}$ & $\begin{array}{c}\text { Temperature } \\
\text { (to maintain } \\
\text { constant at } \\
30^{\circ} \mathrm{C} \text { ) }\end{array}$ & $\begin{array}{c}\text { Power } \\
\text { Consumption } \\
\text { (in } \mathrm{kWh} \text { ) }\end{array}$ \\
\hline 1 & $\begin{array}{l}3: 30 \mathrm{PM} \text { to } \\
4: 00 \mathrm{PM}\end{array}$ & $29^{\circ} \mathrm{C}$ to $30^{\circ} \mathrm{C}$ & .500 \\
\hline 2 & $\begin{array}{l}4: 01 \mathrm{PM} \text { to } \\
4: 15 \mathrm{PM}\end{array}$ & $30^{\circ} \mathrm{C}$ & .238 \\
\hline 3 & $4: 16 \mathrm{PM}$ to & $30^{\circ} \mathrm{C}$ & .189 \\
\hline
\end{tabular}

\begin{tabular}{|c|c|c|c|}
\hline & $4: 30$ PM & & \\
\hline 4 & $\begin{array}{l}4: 31 \mathrm{PM} \text { to } \\
4: 45 \mathrm{PM}\end{array}$ & $30^{\circ} \mathrm{C}$ & .189 \\
\hline 5 & $\begin{array}{l}4: 46 \mathrm{PM} \text { to } \\
5: 00 \mathrm{PM}\end{array}$ & $30^{\circ} \mathrm{C}$ & .174 \\
& $5: 01 \mathrm{PM}$ & $30^{\circ} \mathrm{C}$ & .243 \\
\hline 6 & $5: 30 \mathrm{PM}$ & & \\
\hline & & & $1.533 \mathrm{~kW}$ \\
\hline
\end{tabular}

As shown in the table the heater was turned on for 30 minutes initially it resulted in the increase of temperature by $1^{\circ} \mathrm{C}$. The aim was to keep the room temperature at $30^{\circ} \mathrm{C}$ for two hours. The algorithm discussed in this paper was applied and it is observed from the table that the temperature of the room has been maintained at preset temperature of $30^{\circ} \mathrm{C}$. The table also shows the corresponding power dissipation at different time intervals. It can be inferred from the table that saving= $(1.8 \mathrm{~kW}-1.533 \mathrm{~kW}) / 1.8 \mathrm{~kW}=.1483$ and $\%$ saving is of 14.83 , if heater is set for a specific temperature (near to $30^{\circ} \mathrm{C}$ ) and power consumption is compared with conventional heater for same temperature, (it is assumed that normal heater should be switched off for time duration to be set on specific temperature and consumption is of $1800 \mathrm{~W}$ ) then the power saving is approximately $14.83 \%$.

The novelty of the system is that, the optimized data collected from the PSO algorithm is applied to the hardware to get the required preset temperature of the room.

\section{REFERENCES}

[1] D. Ibrahim: "Teaching digital control using a low-cost microcontroller- based temperature control kit", International Journal of Electrical Engineering Education, 2011

[2] er^ome Henri K"ampf_, Michael Wetter and Darren Robinson: "A comparison of global optimisation algorithms with standard benchmarkfunctions and realworld applications using EnergyPlus", Journal of Building Performance Simulation (ISSN: 1940-1493), vol. 3, num. 2, p. 103-120, Taylor \& Francis, 2010.

[3] Nikita Kukunura, Babu Rao thella, Rajya Lakshmi davuluri: "Sensor deployment using particle swarm optimization", International Journal of Engineering Science and Technology, Vol. 2(10), 5395-5401, 2010.

[4] http://www.ramacorporation.com/Engineer/ Engineerweb. pdf

[5] I.Khan1, N. Javaid12, M. N. Ullah1, A. Mahmood2, M. U. Farooq: "A Survey of Home Energy Management Systems in Future Smart Grid Communications" arxiv1307.7057, 2013

[6] Anita: "An Analysis of Wireless Sensor Networks based on Particle Swarm Optimization", IJCST Vol. 2, Issue 3, I S S N : 0976 - 8491 (On l in e ), 2011

[7] K.Latha, V.Rajinikanth, P.M.Surekha: “ PSO based PID controller design for a class of stable and unstable systems", Hindawi publishing corporation, 2013

[8] M.H.T. Omar, W.M.Ali, M.Z.Mostafa: "Auto tuning of PID controller using swarm intelligence", International review of automatic control, may 2011 
[9] Ching-Chang Wong, Shih-An Li and Hou-Yi Wang: "Optimal PID Controller Design for AVR System", Tamkang Journal of Science and Engineering", Vol. 12, No. 3, pp. 259_270 (2009)

[10] Shashank Sultaniya and Dr. Rajeev Gupta: "Design of PID Controller using PSO Algorithm for CSTR System", International Journal of Electronic and Electrical Engineering. ISSN 0974-2174 Volume 7, pp. 971-977, Number 9 (2014).

[11] Vineet Shekher, Dr. Pankaj Rai, Dr. Om Prakash: "Design and Evaluation of Classic PID, Gain and Phase Margin Based Controller and Intelligent Controller Design for a Ceramic Infrared Heater" , ARPN Journal of Science and Technology, VOL. 3, NO. 3,ISSN 22257217, April 2012.
[12] Mohammad Ahmadi, Mohammadsoroush Soheilirad:, "PI-Controller Adjustment Using PSO for a Laboratory Scale Continuous Stirred Tank Heater", J. Basic. Appl. Sci. Res., 3(3)123-129, ISSN 2090-4304, 2013.

[13] S.N. Sivanandam, P. Visalakshi, "Dynamic task scheduling with load balancing using parallel orthogonal particle swarm optimization", Inderscience, International Journal of Bio-Inspired Computation 2009 - Vol. 1, No.4 pp. $276-286$

[14] Shinichi Imai, Toru Yamamoto, "Design of a multiple linear models-based PID controller", Inderscience, International Journal of Advanced Mechatronic Systems 2012 - Vol. 4, No.3/4 pp. 141 - 148

[15] Dingue, YangQuan Chen, Derek P. Atherton, "Linear Feedback control", society for Industrial and applied mathematics. 